\title{
Giant chorioangioma with severe polyhydramnios presenting with abruptio placenta: a case report
}

\author{
Subashchandra R. Mudanur, Shreedevi D. Kori, Rajasri G. Yaliwal, Preeti S. Malapure*
}

Department of Obstetrics and Gynecology, Shri B M Patil Medical College, Vijayapura, Karnataka, India

Received: 17 July 2021

Accepted: 09 August 2021

\section{*Correspondence:}

Dr. Preeti S Malapure,

E-mail: preetimalapure1991@gmail.com

Copyright: (C) the author(s), publisher and licensee Medip Academy. This is an open-access article distributed under the terms of the Creative Commons Attribution Non-Commercial License, which permits unrestricted non-commercial use, distribution, and reproduction in any medium, provided the original work is properly cited.

\begin{abstract}
Chorioangioma is the most common placental non trophoblastic tumor which can result in pregnancy complications with attendant maternal and fetal mortality and morbidity. Although majority of them are asymptomatic, clinical course depends mainly on the size of the neoplasm. We present a case of large symptomatic placental chorioangioma of $10 \mathrm{~cm}$ size managed successfully at Shri B M Patil Medical College, Vijayapura, Karnataka, India. The patient presented with acute features of abruptio placenta secondary to sudden decompression of uterus due to rupture of the membranes. Immediate intervention with Emergency LSCS helped to rescue the baby of Intauterine demise and possible hemorrhagic morbidity in the mother. Further gross and histological examination confirmed the diagnosis of giant chorioangioma.
\end{abstract}

Keywords: Chorioangioma, Polyhydramnios, Pregnancy disorders, Ultrasonography placental tumor

\section{INTRODUCTION}

Chorioangioma is noted in $1 \%$ of carefully examined term placenta and is the most common benign tumor of the placenta. They are vascular tumors with the majority being solitary, intraplacental, small sized and encapsulated. By virtue of small size, chorioangiomas are very unlikely to be detected during gross pathological examination, unless the placenta is carefully sectioned and subjected to histological examination. Small chorioangiomas often remain asymptomatic and do not complicate the course of pregnancy. However, Giant chorioangiomas (>5 centimeters in diameter) with an approximate prevalence of around 1 in 9000 to 1 in 50,000 pregnancies,have been associated with many adverse maternal and fetal complications. ${ }^{1}$

Symptoms caused by large placental chorioangiomas are reported to be severe both for mother and fetus. We describe here a case of multigravida.

\section{CASE REPORT}

A 25-year-old G2P1L1 was admitted to the hospital in the 31 st week of gestation with complaint of pain abdomen. Ultrasonography revealed polyhydramnios and a large coarse solid placental hemangioma-like tumor of $10 \mathrm{~cm}$ diameter (Figure 1). Hydrops and fetal tachycardia observed on ultrasound examination aroused suspicion of fetal cardiac failure. She was managed conservatively. The polyhydramnios increased further during the following 2 weeks and she presented with acute pain abdomen, PPROM and vaginal bleeding in the 33rd week of gestation. On examination, she was found to have revealed abruptio placenta with breech presentation and non reassuring NST. The pregnancy was terminated by lower segment cesarean section under epidural anesthesia. The placenta was located in the anterior wall of uterus and the fetal surface of the placenta was occupied by a large tumor (Figure 2). Postpartum recovery was uneventful and she was discharged on 9th day. She delivered a female baby of weight 2610 gram with APGAR (appearance, pulse, 
grimace, activity, and respiration) score 5 and 6 at one and five minutes of birth respectively.

The baby was immediately intubated and transferred to NICU and set on Baby-Bird respirator. She developed no further respiratory problems and was extubated on the first day. She was evaluated for cardiac failure and after 36 hours of digitalis and furosemide treatment the neonate weighed 1970 gram and her cardiac insufficiency had been compensated. The neonate was diagnosed with hemolytic disease without blood group incompatibility and underwent exchange transfusion. The baby was discharged from the hospital after 15 days and her development was normal.

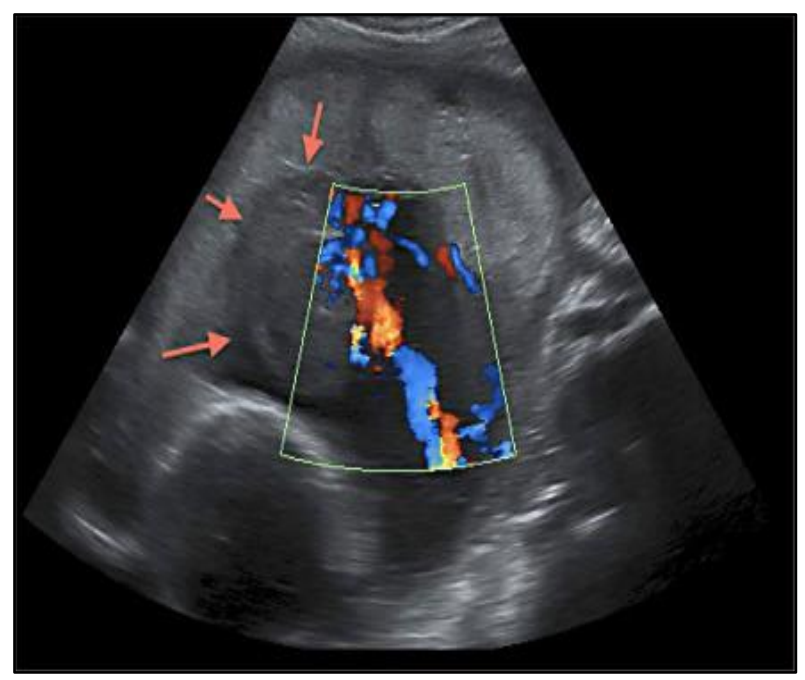

Figure 1: USG showing chorioangioma.

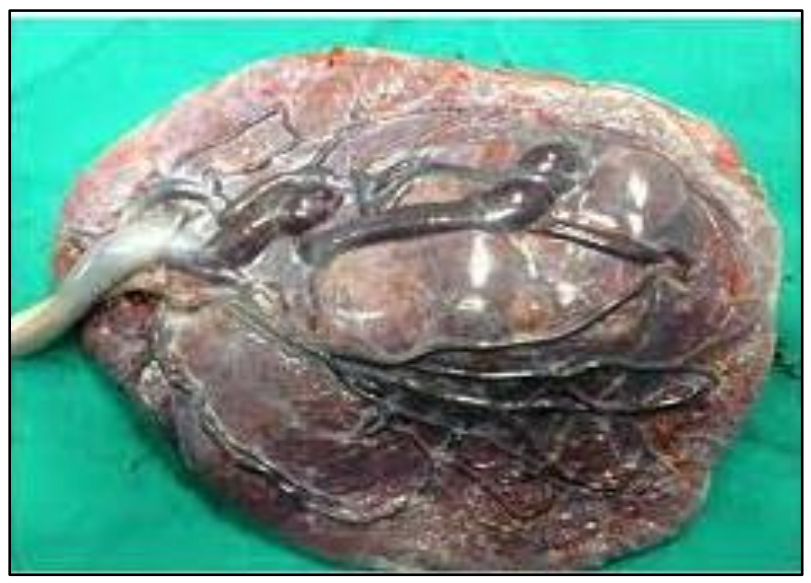

Figure 2: Placenta with chorioangioma.

Pathological examination of the placenta was done. It weighed 1170 gram and measured $23 \times 15 \times 5 \mathrm{~cm}$. There was a bulging protuberance on the fetal surface extending from the margin to the central part near the insertion of the umbilical cord with a short cord of $42 \mathrm{~cm}$ length. The tumor measured $10 \times 8 \mathrm{~cm}$ extending into the placental substance.

\section{DISCUSSION}

Chorioangioma is a benign, vascular, non-trophoblastic neoplasm of the chorionic stroma. It is also called as placental angioma, chorioangioma, angiomyxoma and vascular hamartoma of the placenta. It is characterized by abnormal vascular proliferation within the parenchyma of the placenta. Large placental chorangioma can cause complications in the mother such as polyhydramnios, preterm labour, premature placental separation and placenta previa 2 and fetal complications such as congestive heart failure, thrombocytopenia, nonimmune fetal hydrops, hemolytic anemia, intrauterine growth restriction, brain infarction, umbilical vein thrombosis, fetal cerebral embolism, and intrauterine fetal and neonatal death. ${ }^{3}$ Anemia, thrombocytopenia, congenital anomalies or congestive cardiac failure may be seen in a neonate.

Polyhydramnios has been linked to increased urine production associated with the fetal hyperdynamic circulation related either to shunting of the blood in the placental chorioangioma or fetal anemia. Also, transudation of fluid from the tumor surface adjacent to the placental surface can also lead to polyhydramnios.

On Ultrasonography, Gray-scale findings are well-defined complex echogenic mass different from the rest of placenta and tumor protrudes into amniotic cavity near umbilical cord insertion. Color doppler study can differentiate it from placental teratoma, blood clot, and leiomyoma. On Doppler scan, feeding vessels usually have same pulsatile flow as that of umbilical artery but may have arteriovenous shunt causing low resistance flow. ${ }^{4}$

Management of chorioangioma is usually conservative. Asymptomatic cases are monitored by antenatal USG which is useful for close fetal monitoring and timely intervention if any complications arise. In situations of maternal or fetal complications which necessitate intervention, treatment options include serial fetal transfusions, fetoscopic laser coagulation of vessels supplying the tumor, chemosclerosis with absolute alcohol and endoscopic surgical devascularization. The present case presented with acute placental abruption secondary to sudden decompression of uterus due to PROM in polyhydramnios. Immediate intervention with LSCS helped to save the mother and baby.

\section{CONCLUSION}

Giant chorioangiomas are rare but associated with maternal and fetal complications. Careful evaluation with color doppler will clinch the diagnosis. Meticulous antenatal surveillance helps in reducing the maternal and fetal mortality and morbidity. The case is reported for it's rarity of occurrence and to discuss the diagnosis and optimal management methods.

Funding: No funding sources Conflict of interest: None declared 


\section{Ethical approval: Not required}

\section{REFERENCES}

1. Barros A, Freitas AC, Cabral AJ, Camacho MC, Costa E, Leitao $\mathrm{H}$ et al. Giant placental chorioangioma: a rare cause of fetal hydrops. BMJ Case Reports. 2011;02:3880.

2. Kataria N, Singh A, Bedi PK. Giant Placental Chorangioma: A Rare Case Report. J Clin Diagn Res. 2016;10(4):ED03-4.
3. Bhalla S, Bhatti SG, Garg R. Plancental Chorioangioma: A Rare Cause for Polyhydramnios and Fetomaternal Complications. J South Asian Feder Obst Gynae. 2018;10(4):284-7.

4. Kodandapani S, Shreshta A, Ramkumar V, Rao L. Chorioangioma of placenta: a rare placental cause for adverse fetal outcome. Case Rep Obstet Gynecol. 2012;2012:913878.

Cite this article as: Mudanur SR, Kori SD, Yaliwal RG, Malapure PS. Giant chorioangioma with severe polyhydramnios presenting with abruptio placenta: a case report. Int J Reprod Contracept Obstet Gynecol 2021;10:3644-6. 